\title{
Teriparatide treatment in a heart transplant patient with a chronic kidney disease and a low-turnover bone disease: a case report
}

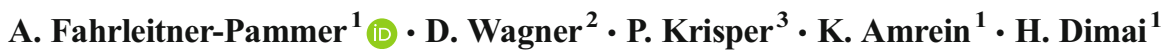

Received: 6 June 2016 / Accepted: 22 November 2016 / Published online: 17 December 2016

(C) The Author(s) 2016. This article is published with open access at Springerlink.com

\begin{abstract}
Low-turnover bone disease is a complication of chronic kidney disease and a long-term steroid therapy. Currently, the only bone anabolic treatment available is teriparatide (TPTD). So far, no data exist in heart transplant patients, and only one single case with histomorphometric analysis of a dialysis patient with a low-turnover bone disease has been published. The current report shows the effect of a 1-year TPTD therapy in a cardiac transplant patient with 10 vertebral and 3 peripheral fractures who had developed a chronic kidney failure while receiving triple immunosuppressive therapy. A transiliac bone biopsy following tetracycline labeling was performed prior and after 1 year of treatment, showing an increase in the bone formation and improvement of the structural indices (20-fold increase of osteoid volume/bone volume, fourfold increase of osteoid surface/bone surface and increases of wall thickness $(+15 \%)$, trabecular thickness $(+9 \%)$, and trabecular number $(+38 \%))$. Bone mineral density was stable, no new vertebral fractures had occurred, the therapy was well-tolerated, and the patient improved clinically.
\end{abstract}

A. Fahrleitner-Pammer

astrid.fahrleitner@medunigraz.at

1 Division of Endocrinology and Diabetes, Department of Internal Medicine, Medical University, Auenbruggerplatz 15, 8036 Graz, Austria

2 Division of Transplantation, Department of Surgery, Medical University, Auenbruggerplatz 17, 8036 Graz, Austria

3 Division of Nephrology and Dialysis, Department of Internal Medicine, Medical University, Auenbruggerplatz 21, 8036 Graz, Austria
Keywords Bone biopsy · Cardiac transplantation . Histomorphometrie $\cdot$ Low-turn over bone disease in CKD-MBD · Teriparatide

\section{Introduction}

Transplantation bone disease and chronic kidney diseasemineral bone disorders (CKD-MBD) are two entities independently associated with a high fracture risk [1,2].

Steroid treatment combined with increasing serum sclerostin levels due to a kidney damage may induce an adynamic bone disease [3-6]. Decreasing kidney function is a common late complication of immunosuppressive therapy and may lead to CKD-MBD [2]. The decrease of bone mass is aggravated by a deterioration of bone microarchitecture not only in transplantation bone disease but also in CKD [7-11]. At the time of initiation of dialysis, $50 \%$ of the patients have prevalent fractures [10-12], and approximately half of the patients on chronic dialysis have a low-turnover bone disease [13]. Whereas there are promising data for denosumab treatment in patients with chronic kidney disease [12], prospective data for teriparatide (TPTD) in CKD patients are scarce $[14,15]$. Only recently, one report of TPTD treatment leading to an improvement of bone remodeling in a dialysis patient was published [16].

We report on the treatment effects of TPTD on the histomorphometric indices, bone mineral density, fractures, and bone metabolism in a cardiac transplant patient with stage 4 CKD. 
Table 1 Laboratory results at the baseline and after 1 year of therapy as well as the changes in back pain and health-related quality of life

\begin{tabular}{lll}
\hline Laboratory parameters & Baseline & 1 year \\
\hline S-Creatinine $(0.6-1.3 \mathrm{mg} / \mathrm{dl})$ & 4.4 & 4.8 \\
GFR $\left(>70 \mathrm{ml} / \mathrm{min} / 1.73 \mathrm{~m}^{2}\right)$ & 21 & 19 \\
S-Phosphate $(0.87-1.45 \mathrm{mmol} / \mathrm{l})$ & 1.35 & 1.24 \\
S-Calcium $(2.2-2.65 \mathrm{mmol} / \mathrm{l})$ & 1.91 & 2.39 \\
bALP $(14-43 \mathrm{U} / \mathrm{L})$ & 34 & 45 \\
TRAP5b $(0.61-3.45 \mathrm{U} / \mathrm{l})$ & 3.32 & 3.87 \\
sCTX $(0.03-0.44 \mathrm{ng} / \mathrm{ml})$ & 1.55 & 1.87 \\
Osteocalcin $(1-35 \mathrm{ng} / \mathrm{ml})$ & 87 & 123 \\
PINP $(20-75 \mathrm{ng} / \mathrm{ml})$ & 184 & 546 \\
iPTH $(15-65 \mathrm{pg} / \mathrm{ml})$ & 112 & 98 \\
25(OH)VitD $(30-65 \mathrm{ng} / \mathrm{ml})$ & 31 & 34 \\
EQ-5D [5-15] & 11 & 7 \\
EQ-VAS $(0-100)$ & 85 & 40 \\
\hline
\end{tabular}

\section{Case}

A 58-year-old white man who had received a cardiac transplant due to myocarditis 7 years earlier was followed up at the Medical University Graz, a tertiary center in the southern part of Austria, Europe. The first osteoporosis assessment of the patient was carried out 2 months following surgery. According to the WHO classification, osteopenia was diagnosed by measuring the bone mineral density (BMD) - using the dual X-ray technology (GE Lunar iDXA, GE Healthcare, $\mathrm{UK}$ - - at the spine $\left(0.688 \mathrm{~g} / \mathrm{cm}^{2}\right.$, T-score -2.4$)$, the neck region of the hip $\left(0.698 \mathrm{~g} / \mathrm{cm}^{2}\right.$, T-score -1.9$)$, and the total region of the hip $\left(0.762 \mathrm{~g} / \mathrm{cm}^{2}, \mathrm{~T}\right.$-score -1.8$)$. A standardized spinal X-ray revealed one moderate vertebral fracture according to the Genant classification [17]. The patient had no history of peripheral fractures or previously diagnosed osteoporosis. He received a triple immunosuppressive therapy consisting of $5 \mathrm{mg}$ aprednisolone, cyclosporine A and mycophenolate mofetil, had normal laboratory results including normal kidney function, and was started on bisphosphonate

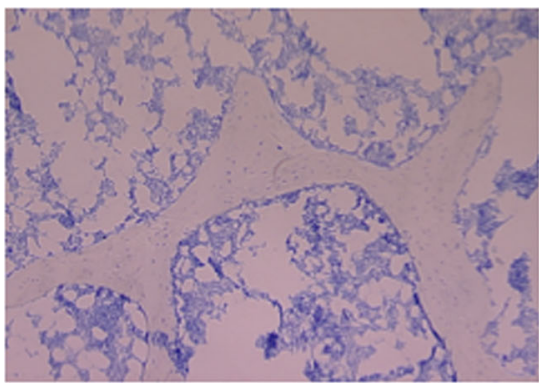

Fig. 1 On the left hand, a hematoxylin and eosin staining of the bone biopsy prior to TPTD shows a lack of osteoid surfaces, eroded surfaces, no osteoblasts or osteoclasts reflecting a low bone turnover. The therapy with quarterly intravenous ibandronate $2 \mathrm{mg}$ on top of the daily $500 \mathrm{mg}$ calcium and $1200 \mathrm{IU}$ cholecalciferol (Vitamin D) [8]. After 2 years, the patient was lost to follow up but returned 5 years later due to an acute back pain. He was still on the same triple immunosuppressive therapy and had developed impaired kidney function (GFR $21 \mathrm{ml} / \mathrm{min} /$ $1.73 \mathrm{~m}^{2}$ ). Other lab results showed a normal serum calcium and phosphate, elevated serum levels of iPTH, crosslaps (sCTX), osteocalcin (OC), procollagen type I N propeptide (PINP) [18] - due to accumulation with decreased renal function [18-21] — and normal levels of $25(\mathrm{OH})$ vitamin D (VitD), 5 tartrate-resistant acid phosphatase (TRAP5b), and bone alkaline phosphatase (bALP) (see Table 1). He had stopped bisphosphonate therapy 4 years ago and was currently receiving $500 \mathrm{mg}$ calcium carbonate as a phosphate binder twice daily, as well as 2000 IU vitamin D. During the past 2 years, he had sustained a wrist fracture, a rib fracture, and an ankle fracture. A standardized X-ray of the spine revealed 10 vertebral fractures -4 severe, 1 moderate, and 5 mildaccording to [17]. BMD measurement was invalid at the spine due to vertebral fractures and aortic calcification (Agatston score 804). BMD at the hip region was severely reduced [neck $0.453 \mathrm{~g} / \mathrm{cm}^{2} \mathrm{~T}$-score -3.9 ) and total hip $0.526 \mathrm{~g} / \mathrm{cm}^{2}$ (T-score -3.4 ] reflecting a loss of 35 and $34 \%$ compared to the BMD results obtained 7 years earlier on the same DXA device. Iliac crest biopsy following tetracycline double labeling was performed. Histomorphometric analysis (OSTEOMEASURE) revealed an adynamic bone disease and destroyed bone microarchitecture (see Fig. 1 and Table 2) [22] with reduced osteoid and eroded surface and an absence of double labels - only two single labels could be defined.

The patient was trained on self-injections with TPTD. Serum calcium and phosphate levels stayed within a normal range and were monitored daily, later at least every other week. Serum PTH and vitamin D levels did not change, bone markers increased, and kidney function remained stable (Table 1). The patient improved clinically with an increase of the HRQoL (EQ-5D) and a decrease of the EQ-VAS score (Table 1). After 1 year, a second bone biopsy showed

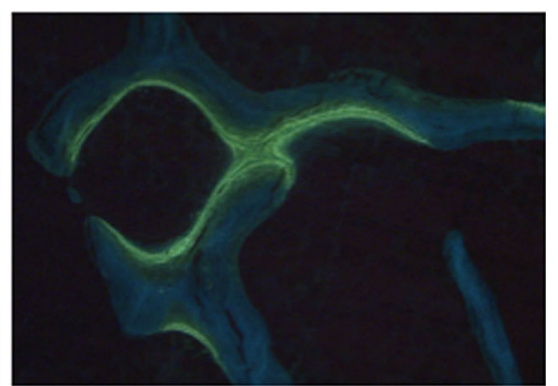

unstained cut at the baseline had no double labels. The unstained cut on the right shows double tetracyline labels under teriparatide therapy - the biopsy was taken after 1 year of TPTD treatment 
Table 2 Histomorphometric parameters prior and after 12 months of teriparatide therapy—parameter and abbreviation according to (23). The reference range refers to (24)

\begin{tabular}{lll}
\hline Measurements & $\begin{array}{l}\text { Pre-teriparatide } \\
\text { therapy }\end{array}$ & $\begin{array}{l}\text { Post-teriparatide therapy (\% } \\
\text { change) }\end{array}$ \\
\hline Bone volume/tissue volume (BV/TV) $14-30 \%$ & 6.7 & $8.0(+19)$ \\
Osteoid surface/bone surface (OS/BS) 7-25\% & 4.8 & $17.7(+269)$ \\
Osteoid volume/bone volume (OV/BV) $0.3-3.1 \%$ & 0.07 & $1.4(+1900)$ \\
Osteoblast surface/bone surface (ObS/BS) $0-9.5 \%$ & 0 & $4.5(\mathrm{NA})$ \\
Eroded surface/bone surface (ES/BS) 1.75-7.0\% & 0.2 & $1.85(+825)$ \\
Osteoclast surface/bone surface (OCS/BS) $0.0-2.0 \%$ & 0.1 & $0.4(+300)$ \\
Wall thickness (W. Th) 25.0-38.0 $\mu \mathrm{m}$ & 17.6 & $20.3(+15)$ \\
Trabecular number (TbN) 1.2-2.0/mm & 0.89 & $1.23(+38)$ \\
Trabecular thickness (TbTh) 127-165 $\mu \mathrm{m}$ & 116.4 & $865(-12)$ \\
Trabecular separation (Tb/Sp) 480-850 $\mu \mathrm{m}$ & 987 & $17.9(+752)$ \\
Mineralizing surface single label/bone surface & 2.1 & $0.39(\mathrm{NA})$ \\
$\quad$ MS/BS) 1.4-18\% & 0 & \\
Mineral apposition rate (MAR) $0.36-0.63 \mu \mathrm{m} / \mathrm{d}$ & &
\end{tabular}

improvements of static and dynamic parameters (Table 2) (Fig. 1). After TPTD was initiated, no new peripheral fracture occurred, BMD remained stable, and spinal X-ray revealed no new fracture but worsening of one mild to a moderate vertebral fracture. No adverse events or rejection episodes occurred.

In total, the patient has received TPTD for 24 months, and he is currently under denosumab $60 \mathrm{mg}$ twice a year.

\section{Discussion}

To our knowledge, this is the first case report on TPTD treatment in transplantation bone disease describing a beneficial effect on bone remodeling. This case grows intricate due to the adynamic bone disease as a likely consequence of a long-term steroid treatment, aggravated by chronic kidney disease. In the recently published report of a dialysis patient without concomitant immunosuppressive therapy, positive effects on bone remodeling have been published [16]. That 41-year-old dialysis patient showed a marked improvement of histomorphometric parameters after 2 years of TPTD, together with a marked increase in BMD. Similar to this case, our patient responded to TPTD with a near fourfold increase of OS/BS, a 20-fold increase of OV, and a normalization of $\mathrm{ObS} / \mathrm{BS}$. Even as soon as after 12 months, the cancellous structural parameter improved (see Table 2). These changes are in line with the data published earlier [22, 25], and only changes in W. Th and BV were smaller - possibly due to the shorter treatment duration. Compared to [16], in the case described here, a marked anabolic effect was seen, with a manifold increase of the bone formation indices. There is strong evidence that the early period of TPTD treatment is dominated by a bone formation [26, 27]. Our patient had his second biopsy after 1 year. Likely, a chronic steroid therapy and a low-turnover CKD-MBD accounted for a delayed response to TPTD, and the excessive response of bone formation in this patient reflects the early predominately anabolic effect [27]. In CKD patients with a low-turnover bone disease, TPTD seems to increase BMD [15, 28], but the data on histomorphometric response are limited to one case [16]. With denosumab, a treatment option for patients with normal- to high-turnover CMD, MBD has become available [12], but again histomorphometric data in CKD patients are lacking.

The opportunity to treat a high-turnover bone disease in a kidney failure with denosumab and a low-turnover CKD-MBD with TPTD on the one hand and the lack of any prospective interventional studies, so far, must encourage clinicians to start treating patients according to their underlying pathophysiology which can be assessed using histomorphometric diagnosis of bone turnover status. It must be acknowledged, however, that not a single prospective interventional study exists so far.

Our case demonstrates that even in a CKD-MBD patient with a triple immunosuppressive therapy including a lifelong treatment with steroids, adynamic bone disease responds to teriparatide treatment and leads to a normalization of the dynamic parameters and improvement of the structural indices.

Acknowledgments Open access funding provided by Medical University of Graz.

\section{Compliance with ethical standards}

\section{Conflicts of interest None.}

Open Access This article is distributed under the terms of the Creative Commons Attribution-NonCommercial 4.0 International License (http:// creativecommons.org/licenses/by-nc/4.0/), which permits any noncommercial use, distribution, and reproduction in any medium, provided you give appropriate credit to the original author(s) and the source, provide a link to the Creative Commons license, and indicate if changes were made. 


\section{References}

1. Cohen A, Sambrook P, Shane E (2004) Management of bone loss after organ transplantation. J Bone Miner Res 9:1919-1932

2. Ketteler M, Elder GJ, Evenepoel P, Ix JH, Jamal SA, Lafage-Proust MH et al (2015) Revisiting KDIGO clinical practice guideline on chronic kidney disease - mineral and bone disorder: a commentary from a Kidney Disease: improving global outcomes controversies conference. Kidney Int 87:502-528

3. Pelletier S1, Confavreux CB, Haesebaert J, Guebre-Egziabher F, Bacchetta J, Carlier MC et al (2015) Serum sclerostin: the missing link in the bone-vessel cross-talk in hemodialysis patients? Osteoporos Int 26(8):2165-2174

4. Pelletier S, Dubourg L, Carlier MC, Hadj-Aissa A, Fouque D (2013 May) The relation between renal function and serum sclerostin in adult patients with CKD. Clin J Am Soc Nephrol 8(5):819-823

5. de Oliveira RA, Barreto FC, Mendes M, dos Reis LM, Castro JH, Britto ZM et al (2015 May) Peritoneal dialysis per se is a risk factor for sclerostin-associated adynamic bone disease. Kidney Int 87(5): 1039-1045

6. Moysés RM, Schiavi SC (2015 Nov-Dec) Sclerostin, osteocytes, and chronic kidney disease - mineral bone disorder. Semin Dial 28(6):578-586

7. Miller PD (2014 Aug) Bone disease in CKD: a focus on osteoporosis diagnosis and management. Am J Kidney Dis 64(2):290-304

8. Fahrleitner-Pammer A, Piswanger-Soelkner JC, Pieber TR, Obermayer-Pietsch BM, Pilz S, Dimai HP et al (2009) Ibandronate prevents bone loss and reduces vertebral fracture risk in male cardiac transplant patients: a randomized double-blind, placebo-controlled trial. J Bone Miner Res 24:1335-1344

9. Malluche HH, Porter DS, Monier-Faugere MC, Mawad H, Pienkowski D (2012) Differences in bone quality in low- and high-turnover renal osteodystrophy. J Am Soc Nephrol 23:525-532

10. Jamal SA, Gilbert J, Gordon C, Bauer DC (2006) Cortical pQCT measures are associated with fractures in dialysis patients. J Bone Miner Res 21:543-548

11. Nickolas TL1, Leonard MB, Shane E (2008) Chronic kidney disease and bone fracture: a growing concern. Kidney Int 74:721-731

12. Jamal SA1, Ljunggren O, Stehman-Breen C, Cummings SR, MR MC, Goemaere S (2011) Effects of denosumab on fracture and bone mineral density by level of kidney function. J Bone Miner Res 26:1829-1835

13. Malluche HH, Mawad HW, Monier-Faugere MC (2011) Renal osteodystrophy in the first decade of the new millennium: analysis of 630 bone biopsies in black and white patients. J Bone Miner Res 26:1368-1376

14. Cejka D, Kodras K, Bader T, Haas M (2010) Treatment of hemodialysis-associated adynamic bone disease with teriparatide (PTH1-34): a pilot study. Kidney Blood Press Res 33:221-226

15. Miller PD, Schwartz EN, Chen P, Misurski DA, Krege JH (2007) Teriparatide in postmenopausal women with osteoporosis and mild or moderate renal impairment. Osteoporos Int 18(1):59-68
16. Palcu P, Dion N, Ste-Marie LG, Goltzman D, Radziunas I, Miller PD et al (2015) Teriparatide and bone turnover and formation in a hemodialysis patient with low-turnover bone disease: a case report. Am J Kidney Dis 65:933-936

17. Genant HK, Jergas M, Palermo L, Nevitt M, Valentin RS, Black D, et al. Comparison of semiquantitative visual and quantitative morphometric assessment of prevalent and incident vertebral fractures in osteoporosis. The study of osteoporotic fractures research group J Bone Miner Res 1996;11(7):984-996.

18. Krege JH, Lane NE, Harris JM, Miller PD (2014) PINP as a biological response marker during teriparatide treatment for osteoporosis. Osteoporos Int 25(9):2159-2171

19. Delanaye P, Souberbielle JC, Lafage-Proust MH, Jean G, Cavalier E (2014) Can we use circulating biomarkers to monitor bone turnover in CKD haemodialysis patients? Nephrol Dial Transplant 29: 997-1004

20. Cavalier E, Bergmann P, Bruyère O, Delanaye $P$, Durnez A, Devogelaer JP et al (2016) The role of biochemical of bone turnover markers in osteoporosis and metabolic bone disease: a consensus paper of the Belgian Bone Club. Osteoporos Int 27:2181-2195

21. Fahrleitner-Pammer A, Herberth J, Browning SR, ObermayerPietsch B, Wirnsberger G, Holzer H et al (2008) Bone markers predict cardiovascular events in chronic kidney disease. J Bone Miner Res 23(11):1850-1858

22. Jiang Y, Zhao JJ, Mitlak BH, Wang O, Genant HK, Eriksen EF (2003) Recombinant human parathyroid hormone (1-34) [teriparatide] improves both cortical and cancellous bone structure. J Bone Miner Res 18:1932-1941

23. Dempster DW, Compston JE, Drezner MK, Glorieux FH, Kanis JA, Malluche $\mathrm{H}$ et al (2013) Standardized nomenclature, symbols, and units for bone histomorphometry: a 2012 update of the report of the ASBMR Histomorphometry Nomenclature Committee. J Bone Miner Res 28:2-17

24. Recker RR, Kimmel DB, Parfitt AM, Davies KM, Keshawarz N, Hinders S (1988) Static and tetracycline-based bone histomorphometric data from 34 normal postmenopausal females. J Bone Miner Res 3:133-144

25. Dempster DW, Cosman F, Kurland ES, Zhou H, Nieves J, Woelfert L et al (2001) Effects of daily treatment with parathyroid hormone on bone microarchitecture and turnover in patients with osteoporosis: a paired biopsy study. J Bone Miner Res 16(10):1846-1853

26. Dobnig H, Sipos A, Jiang Y, Fahrleitner-Pammer A, Ste-Marie LG, Gallagher JC (2005) Early changes in biochemical markers of bone formation correlate with improvements in bone structure during teriparatide therapy. J Clin Endocrinol Metab 90:3970-3977

27. Lindsay R, Zhou H, Cosman F, Nieves J, Dempster DW, Hodsman $\mathrm{AB}$ (2005) Effects of a one-month treatment with PTH(1-34) on bone formation on cancellous, endocortical, and periosteal surfaces of the human ilium. J Clin Endocrinol Metab 90:3970-3977

28. Mitsopoulos E, Ginikopoulou E, Economidou D, Zanos S, Pateinakis P, Minasidis E (2012) Impact of long-term cinacalcet, ibandronate or teriparatide therapy on bone mineral density of hemodialysis patients: a pilot study. Am J Nephrol 36:238-244 